\title{
Spatial patterns of surface hoar properties and incoming radiation on an inclined forest opening
}

\author{
Eric R. LUTZ, ${ }^{1 *}$ Karl W. BIRKELAND ${ }^{1,2}$ \\ ${ }^{1}$ Department of Earth Sciences, Montana State University, Bozeman, Montana 59717-3480, USA \\ E-mail: snowscience@gmail.com \\ ${ }^{2}$ USDA Forest Service National Avalanche Center, PO Box 130, Bozeman, Montana 59771, USA
}

\begin{abstract}
Avalanche hazard evaluation relies in part on representative snowpack stability observations. Thus, understanding the spatial patterns of snowpack instabilities and their environmental determinants is crucial. This case study integrates intensive field observations with spatial modeling to identify associations between incoming radiation, surface hoar development and its subsequent shear strength across an inclined forest opening. We examined a buried surface hoar layer in southwest Montana, USA, over five sampling days, collecting 824 SnowMicroPen resistance profiles and performing 352 shear frame tests. Spatial models of incoming long- and shortwave radiation were generated for the surface hoar formation period using modeled hemispheric sky visibility, physically based parameters and the Bird Clear Sky Radiation Model in a Geographic Information System. Before burial, the surface hoar persisted despite moderate winds and relatively high air temperatures. The buried surface hoar layer thickness varied between 3 and $21 \mathrm{~mm}$ within a distance of $30 \mathrm{~m}$. Modeled incoming radiation explained spatial variations in layer thickness and shear strength. In areas exposed to large amounts of radiation, the surface hoar layer was strong and thin, while areas with limited incoming radiation (due to high sky visibility and shading) possessed a thicker surface hoar layer that sheared more easily. This demonstrates the usefulness of microclimate modeling for slope-scale avalanche hazard evaluation. We also identify that over the 3 week sample period, strengthening occurred without thinning of the surface hoar layer.
\end{abstract}

\section{INTRODUCTION}

Snow avalanches pose a significant hazard to human populations and infrastructures in mountainous regions worldwide. Avalanche forecasting and hazard reduction methods rely heavily on the evaluation of snowpack information collected in the field. Hence, understanding the spatial patterns of snowpack instabilities and their environmental determinants is crucial. In this case study, we quantify the spatial patterns of the thickness and strength of an observed buried surface hoar layer and test for associations with spatial estimates of incoming radiation during the surface hoar formation period.

Since the 1930s, field studies have documented how environmental factors such as wind, topography, vegetation, and radiation affect slab avalanche formation (e.g. Bader and others, 1939; Gubler and Rychetnik, 1991; Birkeland, 2001; Höller, 2001; Cooperstein and others, 2004; Feick and others, 2007). Such studies have examined relationships across basins or mountain ranges, or identified discrete differences in conditions at paired slopes. Few have quantified the degree to which environmental determinants can influence stability across individual slopes, which is of particular interest for professionals and recreationalists trying to sample slope stability. Birkeland and Chabot (2006) documented that approximately $10 \%$ of stability observations produce stable results when empirical evidence indicated unstable conditions. A portion of this uncertainty in slope-scale hazard evaluation may be resolved by better understanding spatial patterns in stability and environmental determinants at the slope scale.

*Present address: Department of Earth Sciences, Dartmouth College, HB 6105 Fairchild Hall, Hanover, New Hampshire 03755-3571, USA
Studies quantifying the spatial patterns of snowpack stability at the slope scale began in the 1980s when fracture initiation research (e.g. Sommerfeld and Gubler, 1983) sparked debate on how large weak zones need to be to initiate zonal failure (Conway and Abrahamson, 1988; Föhn, 1989; Birkeland and others, 1995; Jamieson, 1995; Kronholm and Schweizer, 2003; Landry and others, 2004; Campbell and Jamieson, 2007; Logan and others, 2007). While potential environmental causes for the observed patterns are often discussed, explicit spatial patterns of environmental determinants at the slope scale have been generally excluded. In this paper, we present research detailed by Lutz (2009) who examined the spatial patterns and temporal development of mechanical and microstructural snowpack properties on an inclined forest opening and tested for spatial associations with terrain, vegetation and radiation variables across the field study site. Such variables may serve as valuable proxies for slope-scale stability evaluation.

\section{METHODS}

\section{Study site}

The study site is located in a montane forest opening in the Henry's Lake Mountains of southwestern Montana, approximately $15 \mathrm{~km}$ west of West Yellowstone, Montana, USA $\left(44^{\circ} 42^{\prime} \mathrm{N}, 111^{\circ} 17^{\prime} \mathrm{W}\right)$. Slope angle ranges between $24^{\circ}$ and $29^{\circ}$ and slope aspect ranges between $34^{\circ}$ and $49^{\circ}$. The surrounding forest is composed primarily of Subalpine fir (Abies lasiocarpa) and Douglas fir (Pseudotsuga menziesii), including two prominent trees at the base of the slope which protrude into the slope's viewshed. The study site itself is sparsely vegetated by grasses, forbs, small shrubs and occasional small coniferous trees and sagebrush. Sheltered 


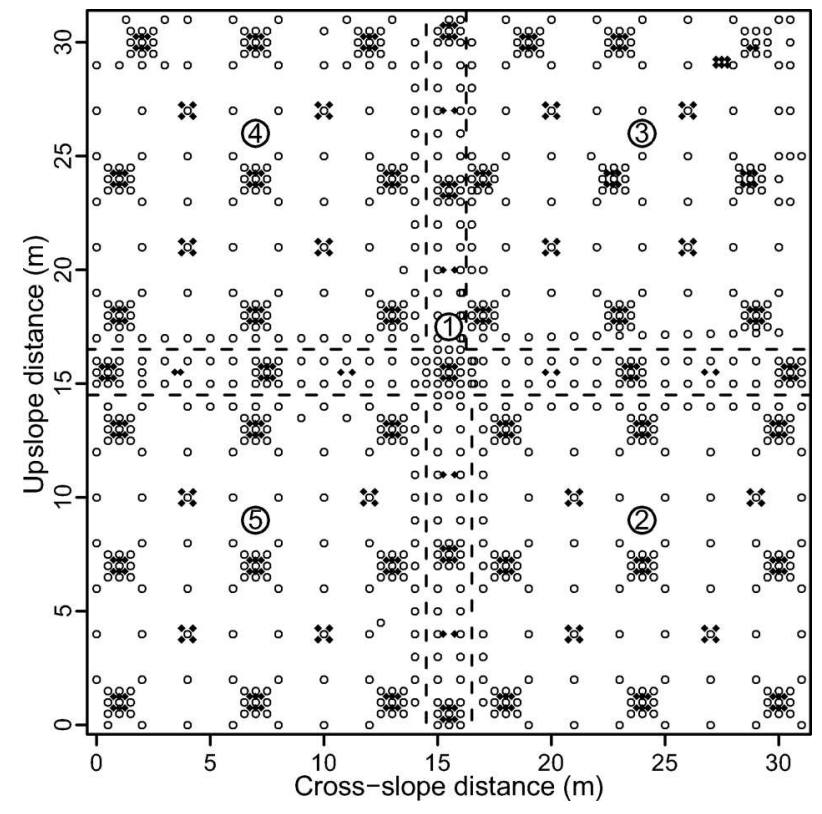

Fig. 1. Sample layout. Dashed lines separate plots $1-5$ (indicated by circled numbers). SMP profiles are circles; shear frame tests are black diamonds.

from westerly ridge-top winds and facing northeast, the study site frequently develops surface hoar in winter, the focus of several past studies (Landry and others, 2004; Logan and others, 2007). Lutz (2009) provides a detailed site description. The study site is located on an unconfined slope, approximately $100 \mathrm{~m}$ below the ridge top and $100 \mathrm{~m}$ above the drainage floor, where a small seasonal (snowmelt-fed) creek exists in spring and summer. No obvious vapor source or confining topographic feature exists on or adjacent to the site.

\section{Overview of field observations}

Winter field observations documented the thickness and shear strength of a buried surface hoar layer that caused snowpack instabilities during the late winter season of 2005. The surface hoar formed during the third week of January 2005 and persisted on the surface for an additional 11 days before it was buried by two small snowfall events in early February. On 28 February 2005, 3 weeks after surface hoar burial, we sampled a cross-shaped plot spanning the entire site (Fig. 1, plot 1). This allowed the quantification of slopescale trends of snow properties at the beginning of the study. Subsequently on 1, 8, 14 and 21 March we sampled the square corner plots (plots 2-5), allowing us to quantify spatial patterns and changes over time.

During the five sampling days, we collected 824 SnowMicroPen (SMP) profiles and 352 shear frame tests, described in detail in the following subsections. The observations were located on a sample layout optimized for geostatistical analysis of SMP profiles and pit-based regression analysis. An effective sample layout captures the existing spatial structures of a natural phenomenon. This particular layout was developed by Lutz (2009) and was found to be more effective than other gridded layouts tested by Kronholm and Birkeland (2007). Although Kronholm and Birkeland (2007) found randomly located observations produce the most reliable estimates, these prove impractical to map in the field and to coordinate spatially coincident observations (SMP and shear frame tests).
At each plot, we nested a majority of the observations in nine clusters, each including six shear frame tests and nine SMP profiles within a $1 \mathrm{~m}^{2}$ surface area (Fig. 1). We refer to these clusters as 'pits', since observers prepared recessed benches for shear frame testing. Previous spatial studies utilizing the SMP centralized all the closely spaced observations in one group near the middle of a plot (e.g. Birkeland and others, 2004; Kronholm and others, 2004; Logan and others, 2007). Alternatively, by distributing the closely spaced observations into nine decentralized clusters, the variance structure at short distances is representative of the entire plot (instead of just the central portion).

We established a slope-oriented coordinate system anchored to wooden posts and rebar that had been fixed on the site perimeter before snowfall. We located sample placements by pulling and offsetting survey tapes between the wooden posts. A Geographic Information System (GIS) that linked sample coordinates with high-resolution terrain and vegetation models allowed the spatial reconstruction of snowpack data.

\section{SnowMicroPen (SMP) measurements and derived surface hoar thickness}

We derived surface hoar thickness, $h_{\mathrm{wl}}$, from penetrometer profiles recorded using the SMP (Schneebeli and Johnson, 1998; Johnson and Schneebeli, 1999) Serial No. 9-9. Previous work identified an inverse relationship between surface hoar thickness and shear strength (Davis and others, 1998; Jamieson and Johnston, 1999; Jamieson and Schweizer, 2000). The sensor resolution and tip size enable thin layers such as surface hoar to be effectively detected (Pielmeier and Schneebeli, 2003). Microstructural information pertinent to snowpack stability (Lutz and others, 2009; Pielmeier and Marshall, 2009) was derived using a micromechanical model (Marshall and Johnson, 2009) and is presented by Lutz (2009).

We assessed and classified the signal quality of all profiles, as defined by Lutz (2009). Signal problems, such as microvariance dampening and artificial drifting, influence signal interpretation and should be accounted for when analyzing SMP signals (Lutz, 2009; Pielmeier and Marshall, 2009). Two main signal criteria assisted in manually delineating $h_{\mathrm{wl}}$ in SMP profiles: (1) the load and fracture signature typical of large hoar crystals interacting with the sensor tip (Johnson and Schneebeli, 1999; Schneebeli and others, 1999) and (2) short (e.g. $0.1-3 \mathrm{~mm}$ ) 'flat line' segments that exhibit no obvious autocorrelation and possess near-zero mean resistance values. Since the adjacent layers were composed of small facets that produced smaller and more frequent loads in the resistance signal, these criteria could be safely assumed.

\section{Shear frame measurements}

Shear frame measurements quantified the in situ shear strength of the targeted buried surface hoar. The shear frame test has been used extensively for avalanche research and forecasting (Schleiss and Schleiss, 1970). The presence of additional buried surface hoar layers in the soft slab above the targeted layer precluded the use of column-type stability tests.

Following standard operating procedure, a $250 \mathrm{~cm}^{2}$ shear frame was positioned within $5 \mathrm{~mm}$ of the boundary between the surface hoar and the superstratum (Perla and Beck, 1983; Sommerfeld, 1984; Greene and others, 2009). Glide-planeparallel force was applied in the downslope direction to a 
force gauge (attached to the shear frame) at a pull rate within the range of brittle fracture (e.g. 1s (Jamieson and Johnston, 2001)). The shear strength, $\tau_{250}(\mathrm{~Pa})$, is defined as the pullgenerated shear force at failure $F_{\text {fail }}$ divided by the tested area $A_{\text {frame, }}$

$$
\tau_{250}=\frac{F_{\text {fail }}}{A_{\text {frame }}} .
$$

We approximated the shear component of force exerted by the experimental set-up, $\tau_{\text {expt. }}$ which is dependent on slope angle, $\alpha$, and the mass of the shear frame, $m_{\text {frame, }}$ and contained snow, $m_{\text {expt.snow, }}$ the latter of which was approximated from slab density measurements such that

$$
\tau_{\text {expt. }}=\frac{g \sin \alpha\left(m_{\text {frame }}+m_{\text {expt.snow }}\right)}{A_{\text {frame }}} .
$$

The total shear stress at failure, $\tau_{\infty}$, was then estimated by multiplying the sum of $\tau_{250}$ and $\tau_{\text {expt }}$ by a size-correction parameter (Sommerfeld, 1984) such that

$$
\tau_{\infty}=\left(\tau_{250}+\tau_{\text {expt }}\right) \times 0.65 \text {. }
$$

\section{Terrain and vegetation observations}

We surveyed topography, vegetation and plot corner markers with a Nikon DTM-500 total station during the snow-free season. Collecting the three-dimensional location of $\sim 2300$ positions within the study site and several hundred surrounding it resulted in a point density greater than 2 points $\mathrm{m}^{-2}$. We also surveyed all woody plants (sagebrush and coniferous trees) taller than $0.4 \mathrm{~m}$ on the site, as well as the height and crown radius and shape of all trees within $30 \mathrm{~m}$ of the study site perimeter (Fig. 2).

A high-resolution $(0.5 \mathrm{~m} \times 0.5 \mathrm{~m})$ elevation model was generated from these points using universal kriging. Crossvalidation calculated RMS (root-mean-square) prediction errors of 0.04-0.05 m (Lutz, 2009). A tree-surface model was generated using inverse-distance weighted interpolations that approximated the size and shape of the observed trees (Lutz, 2009). These surface models could then be integrated with the snow observations.

\section{Weather station}

Meteorological conditions during the surface hoar formation and persistence period were recorded continuously by a weather station located $14 \mathrm{~m}$ upslope of the study site and intermittently by field observers. A Campbell Scientific CR10X data logger recorded snow depth, air temperature and wind speed and direction at $\sim 1.5 \mathrm{~m}$ above ground. Hourly snow-depth measurements using a Campbell Scientific Sonic Ranger 50M-45 allowed us to pinpoint when the surface hoar layer was buried by subsequent snowfall. A Campbell Scientific 107 Temperature Probe with radiation shield recorded hourly average air temperature, and a MetOne 034A wind sensor measured wind speed and direction. The logger saved basic statistics of wind speed and direction to memory every $10 \mathrm{~min}$.

\section{Sky visibility modeling}

Sky visibility, $v_{\%}$, was modeled using a modified viewshed analysis implemented in Arc Macro Language (AML). For each gridcell across the study site, the model calculated the percentage of the hemisphere obstructed by adjacent ground and trees. It builds conceptually on Dozier and Frew (1990) with the distinction of a higher-resolution hemisphere $\left(5^{\circ}\right.$ altitudinal bands, $2^{\circ}$ azimuthal bands) and a terrain model

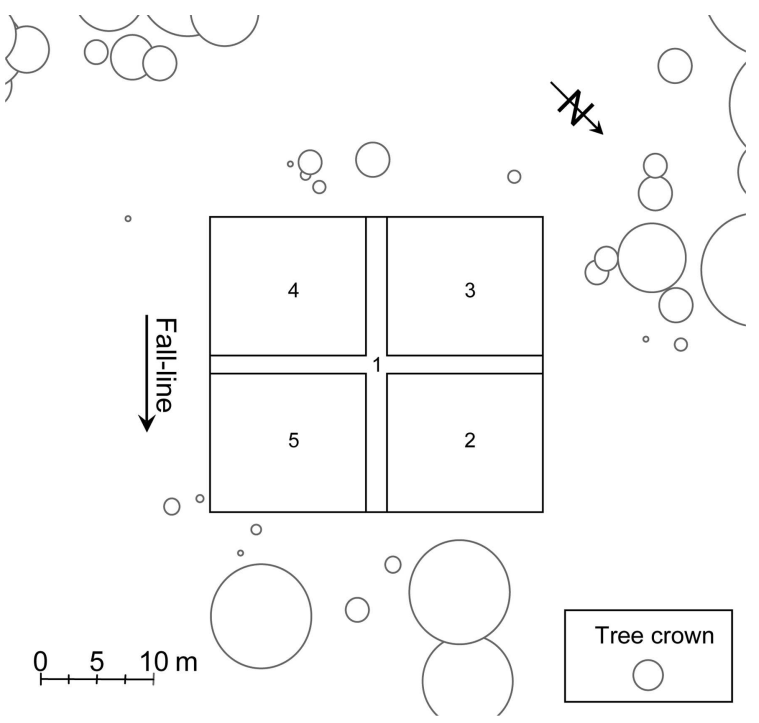

Fig. 2. Map of tree locations proximal to the study site (large square). Tree crowns are represented proportionally as circles. Solid black lines separate plots $1-5$.

that incorporates proximate trees. Lutz (2009) conducted independent optical measurements that produced spatial patterns of $v_{\%}$ similar to those produced by this GIS-based approach $\left(r^{2}=0.89 ; p<0.0001\right)$.

\section{Longwave radiation modeling}

Surface hoar formation and growth depends on the development of a pronounced temperature gradient directly above the snow surface and adequate water vapor supplied through turbulent transfer, fostered by light winds (Nyberg, 1938; Colbeck, 1988; Hachikubo and Akitaya, 1997; Cooperstein, 2008). Determining the spatial patterns of the temperature gradient necessitates measuring the snow surface temperature, $T_{\text {snow }}$ across the site, which was not possible since field observations across the site would mean disturbing the site during the formation period. Remotesensing technologies such as thermographic cameras and small deployable temperature and humidity sensors/loggers were not available at the time of this fieldwork.

Instead, we estimated the spatial pattern of incoming longwave radiation, $L_{\downarrow}$, as a proxy of the night-time cooling potential at the snow surface during the surface hoar formation period. In the absence of shortwave (solar) radiation, the snow surface temperature, $T_{\text {snow }}$ is mainly controlled by the difference between incoming and outgoing longwave radiation fluxes, $L_{\downarrow}$ and $L_{\uparrow}$ respectively, referred to as the net longwave flux, $L_{\text {net }}$. Although the spatial pattern of $L_{\downarrow}$ is nearly identical to that of $V_{\%}$, modeling $L_{\downarrow}$ enabled us to compare the scale of variation (in $\mathrm{W} \mathrm{m}^{-2}$ ) with that of the modeled incoming shortwave radiation.

Based on the Stefan-Boltzmann equation, $L_{\downarrow}$ can be described as a function of the percentage hemispheric viewshed occupied by sky $\left(v_{\%}\right)$ and vegetation $\left(1-v_{\%}\right)$ and their respective emissivity, $\varepsilon$, and temperature, $T$,

$$
L_{\downarrow}=\left(1-v_{\%}\right) \varepsilon_{\text {tree }} \sigma T_{\text {veg }}^{4}+v_{\%} \varepsilon_{\text {air }} \sigma T_{\text {air }}^{4}
$$

with the Stefan-Boltzmann constant of proportionality, $\sigma$, equal to $5.67 \times 10^{-8} \mathrm{~W} \mathrm{~m}^{-2} \mathrm{~K}^{-4}$. As proposed by Bader and Weilenmann (1992) and Höller (2001) for snow-free 
canopies, $T_{\text {tree }}$ was set equal to $T_{\text {air, }}$ reducing Equation (4) to

$$
L_{\downarrow}=\sigma T_{\text {air }}^{4}\left[\left(1-v_{\%}\right) \varepsilon_{\text {tree }}+v_{\%} \varepsilon_{\text {air }}\right] .
$$

This assumption seemed reasonable since under clear-sky conditions the tree surfaces cooled throughout the night. $L_{\downarrow}$ was estimated at locations across the study site as defined in the previous equation, utilizing the GIS-derived estimates of $V_{\%}$. $T_{\text {air }}$ was set to $-1.7^{\circ} \mathrm{C}$ to simulate conditions experienced in the early morning of 20 January, as recorded by the weather station. Following Gubler and Rychetnik (1991) and Höller (2001), $\varepsilon_{\text {tree }}=0.94$ and $\varepsilon_{\text {air }}=0.70$. Because clear skies dominated at night-time we assumed that a relatively low emissivity could be applied. $T_{\text {air }}$ was obtained from weather station measurements on 20 January and was treated as spatially constant across the study site.

\section{Shortwave radiation modeling}

After surface hoar is formed, its preservation depends largely on the snow surface remaining cold. Shortwave radiation heats the snow surface, which hinders crystal growth (by diminishing the air-temperature gradient) and can degrade surface hoar crystals (by metamorphism or melting). Hence, we modeled incoming global shortwave radiation at $15 \mathrm{~min}$ increments for the duration of a clear-sky day using the physically based Bird Clear Sky Model (Bird and Hulstrom, 1981 as implemented by D.R. Myers (http://rredc.nrel.gov/ solar/models/clearsky/BIRD_02_05_2010.xIs)). As with $L_{\downarrow}$, we modeled shortwave radiation instead of solar indices because we wanted to assess the scale of spatial patterns in $\mathrm{W} \mathrm{\textrm {m } ^ { - 2 }}$.

We attempted to measure shortwave radiation with a $\mathrm{LI}$ COR Li-200 pyronometer at the weather stations to verify model output. However, the measurements were not reliable for two reasons: (1) the pyronometer experienced tree shading intermittently throughout the day, including at noon, which made it impossible to compare values from the study site; (2) the sensor had been mounted parallel to the slope to record radiation values that correspond directly with the orientation of the study slope (personal communication from K. Kronholm, 2004). This, however, resulted in highly oblique solar measurements that were influenced by a cosine (i.e. Lambertian) response or effect (Iqbal, 1983).

We ran the Bird model for 20 January, a fairly warm, clear day during the surface hoar formation period for which we had concurrent weather observations. The model produced multiple estimates of solar irradiance, including diffuse and direct irradiance on horizontal surfaces, $I_{\mathrm{ah}}$ and $I_{\mathrm{dh}}$ respectively, as well as the direct irradiance on a surface oriented perpendicular to the solar rays, $I_{\mathrm{db}}$.

The model utilizes several atmospheric parameters. Atmospheric extinction was parameterized using latitude, longitude, time of day and transmission information (atmospheric pressure, precipitable water, aerosol and ozone contents) extrapolated from surrounding weather stations in southwestern Montana and Idaho within $150 \mathrm{~km}$ of the study site (Lutz, 2009). Detailed information about the sensor at these stations, data and data processing is available in NREL (2007). For the Bird model, the extraterrestrial solar constant was set to $1376 \mathrm{~W} \mathrm{~m}^{-2}$ and the snow surface albedo was set to 0.9 .

We integrated the Bird model results into an AML-based GIS model that spatially distributed the diffuse and direct shortwave radiation across the study site incrementally over the modeled day. At 15 min intervals, a discrete hillshade analysis allocated an $I_{\mathrm{db}}$ value of 0 to cells in shaded areas. For non-shaded cells, the wattage of direct shortwave radiation as experienced on variable terrain, $I_{\mathrm{ds}}$, was calculated by scaling $I_{\mathrm{db}}$ by the relative intensity, which is a function of the cosine of the angle of incidence, $\phi$ (the angle between an incoming solar ray, $i$, and the surface normal vector, $s$, at the point of incidence). To achieve this practically in grid-model space, $I_{\mathrm{ds}}$ was calculated using the three-dimensional vector components of $i$ and $s$ such that

$$
I_{\mathrm{ds}}=I_{\mathrm{db}} \times\left(\frac{i_{x} s_{x}+i_{y} s_{y}+i_{z} s_{z}}{\sqrt{i_{x}^{2}+i_{y}^{2}+i_{z}^{2}} \sqrt{s_{x}^{2}+s_{y}^{2}+s_{z}^{2}}}\right),
$$

where $i_{x}, i_{y}$ and $i_{z}$ are the $x-, y$ - and $z$-components of the incoming solar direct radiation vector of strength, $I_{\mathrm{db}}$, and $t_{x^{\prime}}$ $t_{y}$ and $t_{z}$ are the $x-, y$ - and $z$-components of the slope normal vector, $s$. When calculating diffuse shortwave radiation, we followed Wilson and Gallant (2000) and accounted for terrain and trees partially obstructing sky visibility. The diffuse global shortwave radiation on the slope, $l_{\text {as, }}$ was spatially distributed by multiplying $I_{\text {ah }}$ by $V_{\%}$ :

$$
l_{\mathrm{as}}=I_{\mathrm{ah}} \times v_{\%} .
$$

At each time step, the sum of $I_{\text {as }}$ and $I_{\mathrm{ds}}$ equaled the modeled global shortwave irradiance at each gridcell on the snow surface, $I_{\mathrm{s}}$. We did not incorporate reflection from adjacent trees and slopes. Model output presented here includes the maximum global shortwave radiation $I_{\max }$ $\left(\mathrm{W} \mathrm{m}^{-2}\right)$ experienced at each cell location during the day, and the total global shortwave radiation experienced over the course of the day, $\sum I\left(\mathrm{MJ} \mathrm{m}^{-2}\right)$. Additional model outputs are described by Lutz (2009).

\section{Geostatistical analysis}

Geostatistical analysis quantified spatial patterns of $h_{\mathrm{wl}}$ as trend surface and autocorrelation properties, which drove spatial interpolations. R statistical software packages (gstat and $g e o R$ ) facilitated this analysis. Eleven linear and polynomial trend surfaces were tested to describe broad spatial features in the cross-slope, upslope and combined directions (Table 1). Kronholm (2004), Logan and others (2007) and Lutz and others (2007) similarly applied global spatial regression modeling in snow studies. In the absence of significant $(p \leq 0.05)$ spatial trends, the plot mean was assumed the best-fit model. Otherwise, the model with highest significance (smallest $p$-value) was selected. Semivariance analysis tested for positive spatial autocorrelation of residuals of the best-fit trend model. When spatial autocorrelation existed, a spherical semivariogram model was fitted using a weighted least-squares function (Cressie, 1993).

The trend surface and semivariance information drove spatial interpolations of $h_{\mathrm{wl}}$. Depending on the trend surface and autocorrelation properties, local averages were interpolated using the plot mean, global regression, ordinary kriging or universal kriging, as noted below in the results. Lutz (2009) also applied this information to random field interpolations, which can serve as drivers for propagation models (e.g. Kronholm and Birkeland, 2005) and to illustrate how local variability obscures spatial patterns of local mean values.

\section{Linear regression}

Spatially implicit linear associations between radiation and $h_{\mathrm{wl}}$ and $\tau_{\infty}$ were quantified with weighted least-squares 
Table 1. Eleven tested spatial trend surface models. $\beta_{0-i}$ are coefficients, $x$ and $y$ are sample coordinates, $\mu(z)$ is the predicted local mean and $\mu$ is the global mean

\begin{tabular}{lc}
\hline Trend ID. & Mathematical model \\
0 & $\mu(z)=\mu$ \\
1 & $\mu(z)=\beta_{0}+\beta_{1} x$ \\
2 & $\mu(z)=\beta_{0}+\beta_{1} y$ \\
3 & $\mu(z)=\beta_{0}+\beta_{1} x+\beta_{2} y$ \\
4 & $\mu(z)=\beta_{0}+\beta_{1} x y$ \\
5 & $\mu(z)=\beta_{0}+\beta_{1} x+\beta_{2} y+\beta_{3} x y$ \\
6 & $\mu(z)=\beta_{0}+\beta_{1} x^{2}$ \\
7 & $\mu(z)=\beta_{0}+\beta_{1} y^{2}$ \\
8 & $\mu(z)=\beta_{0}+\beta_{1} x+\beta_{2} x^{2}$ \\
9 & $\mu(z)=\beta_{0}+\beta_{1} y+\beta_{2} y^{2}$ \\
10 & $\beta_{0}+\beta_{1} x+\beta_{2} y+\beta_{3} x^{2}+\beta_{4} y^{2}+\beta_{5} y x$ \\
\hline
\end{tabular}

(WLS) regression. First, because both the shear frame and SMP measurements are destructive, they could not be paired spatially on the same unit of snow. Hence, it was not possible to determine whether a relationship existed between the variances of the two types of observations, based on individual pairs of observations. Given that the observations were clustered within tightly spaced local grids (Fig. 1), it was possible to estimate the local variance of both types of observations.

In addition, WLS is useful for small datasets and when the variance of a response variable is inconsistent across the range of explanatory values. The weights were inversely proportional to the variance of the predicted variable across the range of explanatory values. WLS also tested for associations between snow observations grouped by pit. Both snow observation techniques disturb the snowpack and are not spatially coincident, thereby warranting a grouped analysis of nested observations.

\section{RESULTS}

\section{Surface hoar formation}

The presence of hollow columnar surface hoar was observed on 20 January. Crystal height was typically $4-8 \mathrm{~mm}$ but in some instances was up to $15 \mathrm{~mm}$. The crystals consisted of open-sided columns, $\sim 2-4 \mathrm{~mm}$ wide, with distinct scrolling on both columnar edges (Fig. 3). All slope aspects near the site were densely covered. Five days later (25 January 2005), tall plates $(\sim 15 \mathrm{~mm})$ had sprouted from the tops of the hollow columns, now partially decomposed (Fig. 3). This composite crystal structure was observed repeatedly before its burial on 5 February.

\section{Meteorological conditions}

During the second half of January 2005, a diurnal cycle of relatively warm days with light cloud cover and cool clear nights developed. The surface hoar stem structure formed on 20 January. The meteorological conditions on 20 January and preceding days were mostly clear, with a night-time breeze averaging $0-2 \mathrm{~ms}^{-1}$ and maximum gusts less than $10 \mathrm{~m} \mathrm{~s}^{-1}$ (Fig. 4a). Winds were consistently out of the northeast (Fig. 4b), corresponding to an upslope movement, and were probably associated with a regional wind. Temperatures were mild but remained below $0^{\circ} \mathrm{C}$ (Fig. 4c).
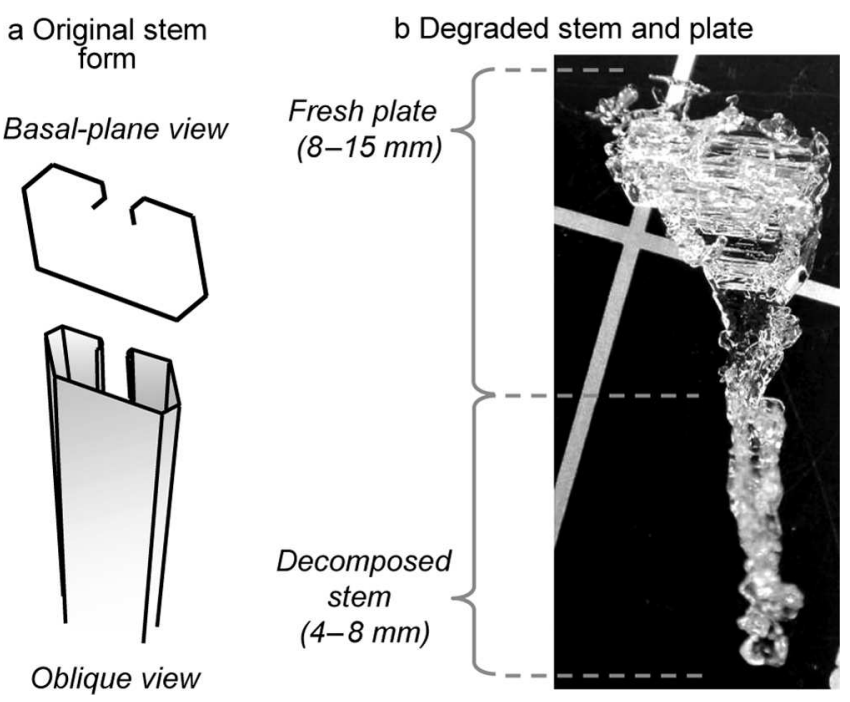

Fig. 3. (a) Enlarged illustration of initial hollow columnar crystal form with scrolling edges on one side, observed on 20 January. (b) Photograph of surface hoar crystal, taken 3 weeks after crystal formation and 10 days after burial; stem and plate structures are evident.

The sprouting plates formed sometime between 20 and 25 January. A diurnal pattern of $T_{\text {air }}$ prevailed, with daily minima $\left(-5^{\circ} \mathrm{C}\right)$ occurring in the early morning and maxima $\left(1-3^{\circ} \mathrm{C}\right)$ occurring in the early afternoon (Fig. 4c). $T_{\text {air }}$ varied by only $8^{\circ} \mathrm{C}$ during these 6 days. A diurnal pattern is also evident in wind speed: morning breezes grew steadily and reached peak values by late afternoon or early evening, with a maximum wind speed of $24 \mathrm{~m} \mathrm{~s}^{-1}$ (Fig. 4a). Winds subsided to complete calm by the late evening or early morning. Winds were generally from the southwest (downslope), although significant shifts occurred during daylight hours (Fig. 4b).

Between 25 January and 5 February, the surface hoar remained exposed on the surface. During this period, $T_{\text {air }}$ reached $0^{\circ} \mathrm{C}$ twice, and on one occasion reached $3^{\circ} \mathrm{C}$. Night-time lows varied between -5 and $-10^{\circ} \mathrm{C}$. Winds were slightly stronger than in previous days but maintained the diurnal pattern. Periods of sustained $5-10 \mathrm{~m} \mathrm{~s}^{-1}$ wind occurred. Clear to partially cloudy conditions persisted throughout the period.

\section{Radiation estimates}

The site-scale spatial pattern of the GIS-distributed estimates of incoming longwave radiation, $L_{\downarrow}$, was slightly concave, with high values at the slope base and along the right and upper edges of the site (Fig. $5 \mathrm{a}$ ). $L_{\downarrow}$ was greatest at the base of the slope where $V_{\%}$ was affected by downslope trees $\left(v_{\%}=57 \%\right)$, and lowest near the middle of plot 4 , where $v_{\%}$ was greatest $\left(v_{\%}=75 \%\right)$. We do not include a map of $v_{\%}$ since it exhibits the same, but inverted, spatial pattern as $L_{\downarrow}$.

We present three estimates of incoming solar radiation, including the maximum global shortwave radiation, $I_{\max }$, the cumulative global shortwave radiation, $\sum l$, and the total exposure time to direct shortwave radiation, $\sum t_{l}$ (Fig. 5). A cross-slope trend existed in $I_{\max }$, with the right half of the site (plots 2 and 3) receiving about $85 \mathrm{~W} \mathrm{~m}^{-2}$ more than the left half of the site (plots 4 and 5). Regarding cumulative solar energy, $\sum l$, plot 2 received the greatest amount of solar energy, and the outer corners of the remaining square plots 


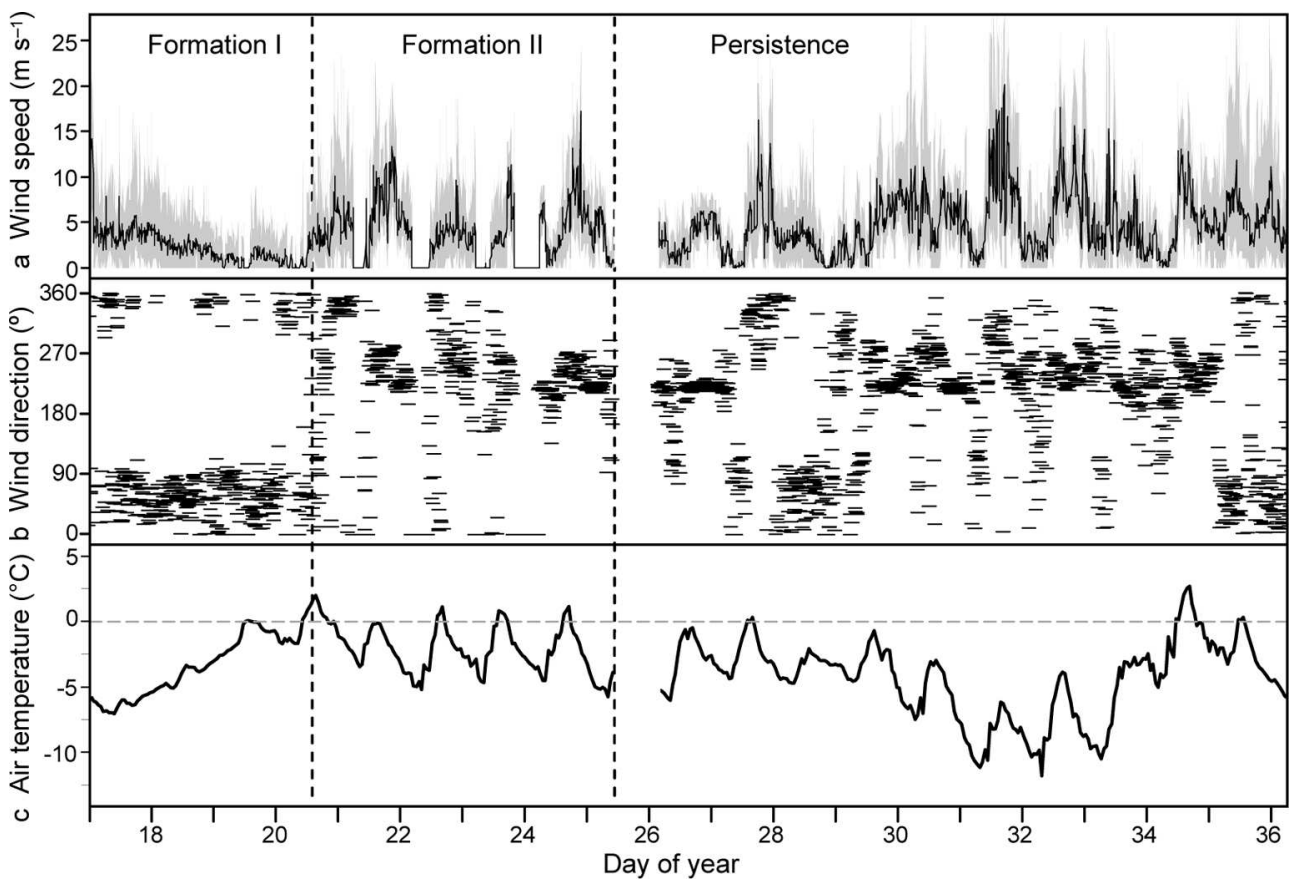

Fig. 4. Meteorological conditions at the study site, 18 January-5 February 2005: (a) wind speed, (b) wind direction and (c) air temperature. Vertical dashed lines demark the first and second formation periods and the persistence period. Gap in coverage on 25 January is concurrent with field maintenance.

received the smallest amounts. Lastly, a site-scale trend of solar exposure time $\sum t_{\text {, }}$ ran diagonally downslope, with the lowest values occurring at plot 3 and the highest values occurring at plot 5 .

\section{Buried surface-hoar layer presence and thickness}

Of 824 SMP profiles, 806 exhibited the surface hoar layer. Nine of the 18 profiles not exhibiting the weak layer were located directly where a rogue ski track had been cut through the outer corner of plot 3 in January (see ' + ' in Fig. 6). Lutz (2009) found no association between the locations of the remaining weak-layer absences and proximity to buried vegetation.

Trend surface analysis showed that weak-layer thickness, $h_{\mathrm{wl}}$, increased in the upslope direction at plots 1, 2 and 5 independently (Table 2; Fig. 6a). This trend was also observed in surface hoar crystal size, observed by the shear frame operator. Individual $h_{\mathrm{wl}}$ values varied between 3 and $21 \mathrm{~mm}$, with the minimum at plot 2 and maximum at plot 4. A subtle but significant cross-slope trend also existed. At common plot boundaries, the local interpolated mean values appear similar between adjacent plots (Fig. 6a). The semivariance analysis showed that at plots 1,2 and 4, $h_{\mathrm{wl}}$ was locally correlated to distances of $2.6,5.0$ and $4.0 \mathrm{~m}$ respectively (Table 2). At plots 3 and $5, h_{\mathrm{wl}}$ had no autocorrelation.

To determine whether $h_{\mathrm{wl}}$ observations from all five plots could be treated as a single site-scale dataset, we tested for significant differences of adjacent observations at plot 1 and the subsequent four square plots (Fig. 7), using the Wilcoxon rank-sum test (Wilcoxon, 1945). For each statistical test, only observations within $2 \mathrm{~m}$ of the common boundary between the compared plots were included. No thinning was evident between the adjacent subsets of these plots

Table 2. Spatial patterns of $h_{\mathrm{wl}}$. Estimates derived from SMP measurements (mm)

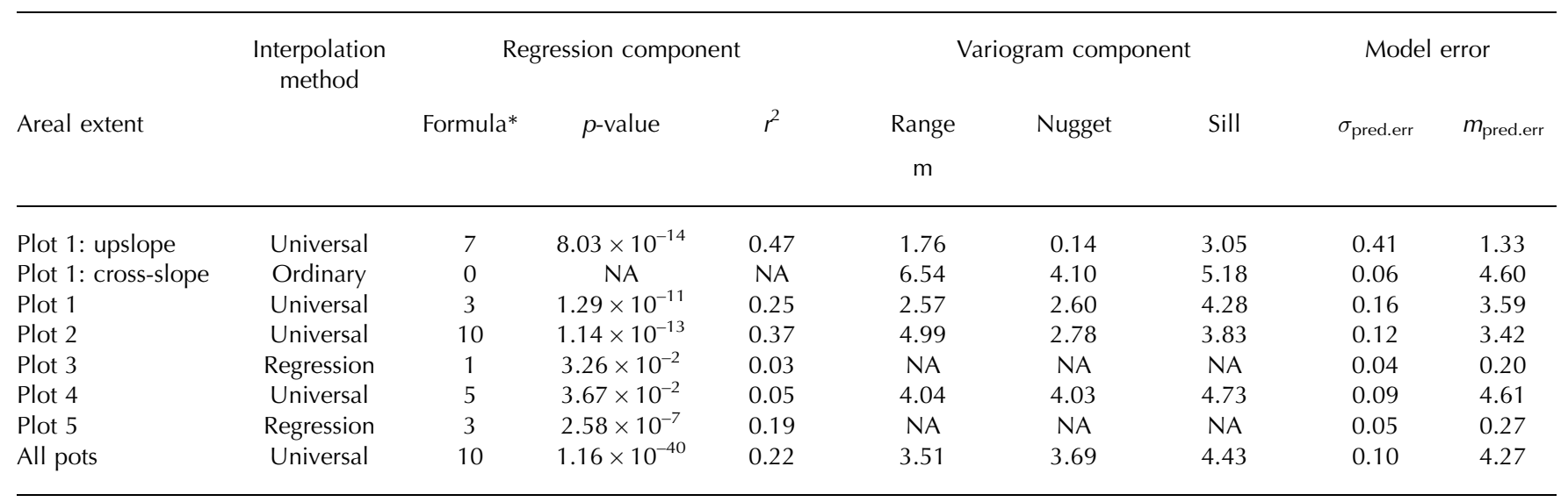

*Best-fit regression model, as defined in Table 1. 

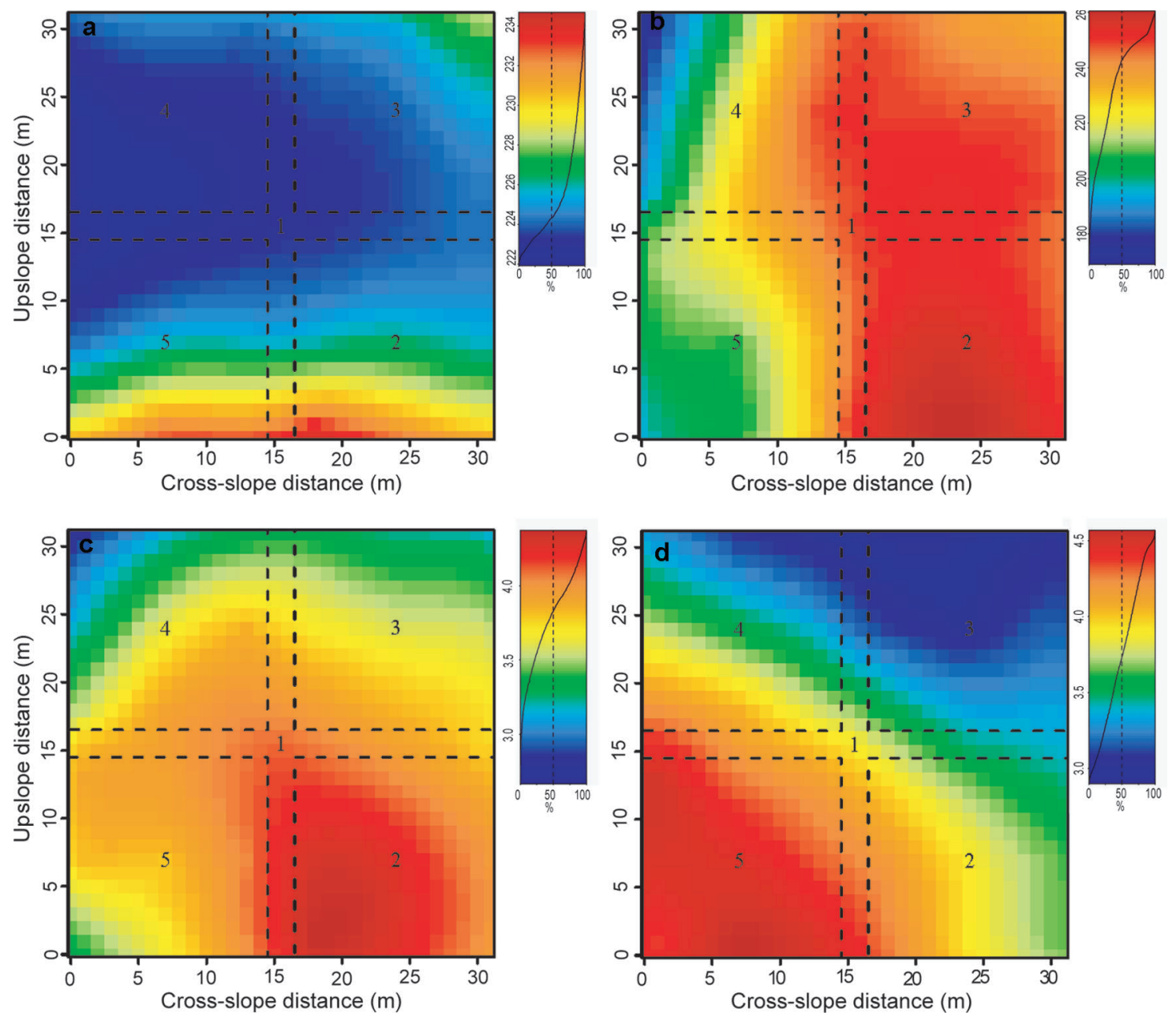

Fig. 5. GIS-distributed radiation estimates: (a) incoming longwave flux $L_{\downarrow}\left(\mathrm{W} \mathrm{m}^{-2}\right)\left(T_{\mathrm{a}}=-1.7^{\circ} \mathrm{C}\right)$, and Bird-model derived estimates of (b) maximum global shortwave radiation $I_{\max }\left(\mathrm{W} \mathrm{m}^{-2}\right)$, (c) cumulative global shortwave radiation $\sum I\left(\mathrm{MJ} \mathrm{m}^{-2}\right)$ and (d) cumulative exposure time to direct shortwave radiation $\sum t_{l}$ (hours). $1 \mathrm{~m}$ resolution. Black lines on scales show cumulative distribution of cell values.
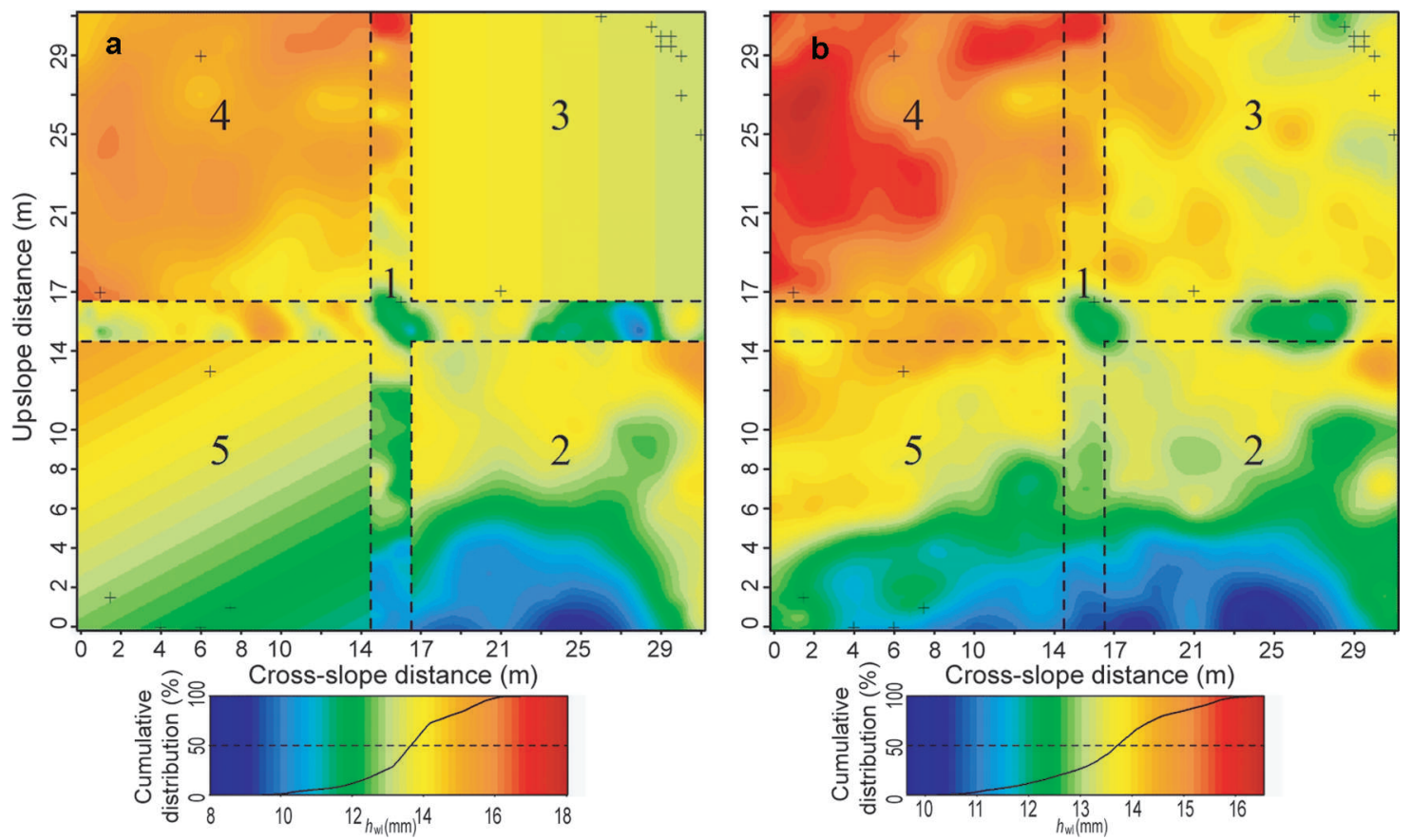

Fig. 6. Spatial interpolations of local mean $h_{\mathrm{wl}}(\mathrm{mm})$ using SMP data (a) from individual plots separately and (b) combined, based on best-fit trend surfaces and semivariance information (Table 2). ' + ' indicates locations where surface hoar was absent in SMP profiles. Black curves on scales show cumulative distribution of cell values. 


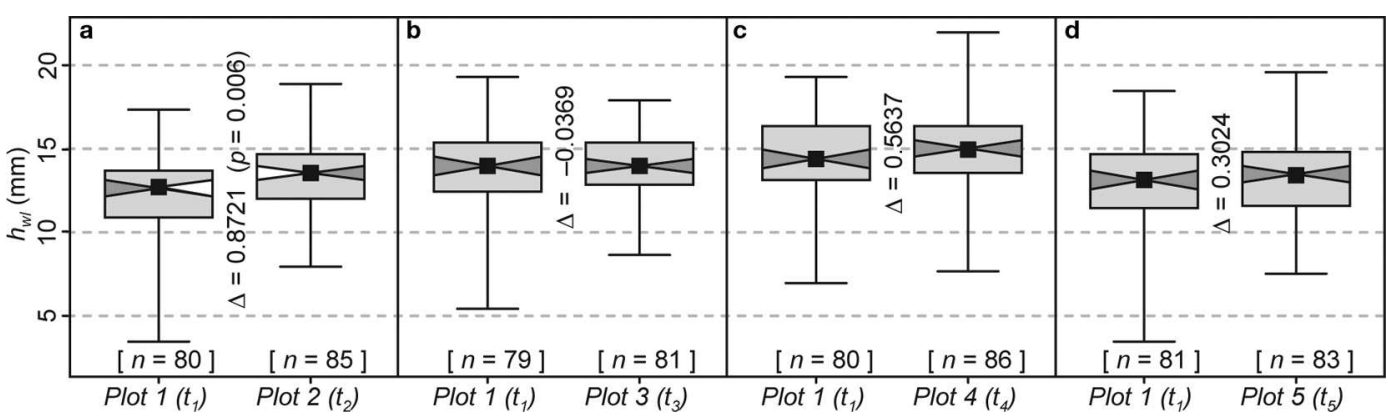

Fig. 7. Box plots compare $h_{w l}$ at initial conditions (plot 1) with adjacent subsets of subsequent plots, namely (a) plot 2, (b) plot 3, (c) plot 4 and (d) plot 5, indicating that surface hoar layer thinning did not occur during the 3 week sampling period. Black square represents the median, whiskers represent the range, and box limits delineate the interquartile range. Triangles on boxes represent approximate $95 \%$ nonparametric confidence intervals of the mean (McGill and others, 1978). The delta value is the difference in medians, accompanied by $p$-value when Wilcoxon rank sum was significant $(p \leq 0.05) . n$ is sample size.

(Fig. 7). Weak-layer thinning may have been difficult to quantify because of the limited slab load which existed for most of the sampling period (Lutz, 2009).

The only significant $(p=0.006)$ difference was plot 2 possessing a thicker surface hoar layer than plot 1, which was probably a spatial phenomenon. Because no thinning was evident between the initial and subsequent observations along common plot boundaries, we considered it appropriate to also analyze all $h_{\mathrm{wl}}$ observations as a large site-scale dataset (Table 5; Fig. 6b). Both interpolations clearly show that $h_{\mathrm{wl}}$ was at a minimum at the base of the slope and was greatest in the upper left corner of the site in plot 4 (Fig. 6).

\section{Snowpack associations with radiation estimates}

Significant $(p \leq 0.05)$ inverse linear relationships existed between $h_{\mathrm{wl}}$ and all radiation estimates at the site scale, i.e. when all observations were included and when only plot 1 observations were included (Table 3 ). Positive correlations between $h_{\mathrm{wl}}$ and $v_{\%}$ mirror those with $L \downarrow$ (recall that the spatial pattern of $L \downarrow$ is largely determined by $\left.v_{\%}\right)$. Significant correlations also existed at the smaller spatial extents for $L \downarrow$ at plots 2 and 5 , for $I_{\max }$ at plot 2 and for $\sum t_{l}$ at $p$ lot 4 . All significant fits indicate that $h_{\mathrm{wl}}$ decreased with increasing exposure to longwave and shortwave radiation.

Unlike surface hoar thickness $h_{\mathrm{wl}}$, shear strength $\tau_{\infty}$ changed significantly over time (Lutz, 2009). Thus, site-scale correlations between $\tau_{\infty}$ and radiation estimates could not utilize observations from all plots pooled together because that would incorporate variance associated with shear strengthening observed over the sampling period. At plot
1, which spanned the entire site, significant positive linear correlations were identified between pit estimates of $\tau_{\infty}$ and the shortwave radiation variables $\sum l$ and $\sum t_{l}$ (Table 4), indicating that higher shear strength was indirectly associated with greater exposure to solar radiation at the site scale. No significant correlations existed between $\tau_{\infty}$ and $I_{\max }$ or $L \downarrow$ at the plot scale.

\section{Direct associations between surface hoar thickness and shear strength}

Significant inverse linear relationships existed between $h_{\mathrm{wl}}$ and $\tau_{\infty}$ on the upper slope, at plots 3 and 4 in the WLS analysis (Table 5). At these plots, the regression fits indicate that shear strength increased across space at a rate of 52 and $88 \mathrm{~Pa} \mathrm{~mm}^{-1}$, respectively. All other plots had no significant relationship between observations grouped by pit, although the signs of the fitted lines were generally also negative.

\section{DISCUSSION}

\section{Meteorological conditions during surface hoar formation and persistence}

The composite stem-plate structure of the surface hoar crystals resulted from two consecutive crystal growth regimes (Jamieson and Schweizer, 2000). General meteorological conditions for both formation periods can be drawn from the weather station data. The surface hoar stem crystals formed during light wind conditions, which are known to foster hoar formation through turbulent transfer of water

Table 3. WLS regression fits between $h_{\mathrm{wl}}$ and sky visibility and radiation estimates*

\begin{tabular}{|c|c|c|c|c|c|c|c|c|c|c|c|c|c|c|c|c|c|c|c|c|}
\hline \multirow{2}{*}{$\begin{array}{l}\text { Spatial } \\
\text { extent }\end{array}$} & \multicolumn{4}{|c|}{$h_{\mathrm{wl}} \sim v_{\%}$} & \multicolumn{4}{|c|}{$h_{\mathrm{wl}} \sim L \downarrow$} & \multicolumn{4}{|c|}{$h_{\mathrm{wl}} \sim I_{\max }$} & \multicolumn{4}{|c|}{$h_{\mathrm{wl}} \sim \sum l$} & \multicolumn{4}{|c|}{$h_{\mathrm{wl}} \sim \sum t_{l}$} \\
\hline & $p$ & $r^{2}$ & $b$ & $m$ & $p$ & $r^{2}$ & $b$ & $m$ & $p$ & $r^{2}$ & $b$ & $m$ & $p$ & $r^{2}$ & $b$ & $m$ & $p$ & $r^{2}$ & $b$ & $m$ \\
\hline & & & & & & 2 & 92 & & & & & & & 2 & & 9 & & & & 66 \\
\hline Plot 1 & & 0.47 & -3.6 & & & 0.48 & 89.1 & $1-0$ & & 0.35 & $36.2-$ & -0 & $0^{-3}$ & 0.57 & & 2 & $\mathbf{9 . 0} \times 10^{-5}$ & 0.77 & & 36 \\
\hline Plot 2 & 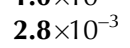 & 0.74 & -3.7 & & 3 & 0.74 & 90 & -0 & -2 & 0.50 & 49.1 & -0. & $5.1 \times 10^{-1}$ & 0.07 & 19 & -1.68 & $8.3 \times 10^{-2}$ & 0.37 & 35.1 & -5.33 \\
\hline Plot 3 & $9 \times 10$ & 0.03 & 8.9 & & $6.4 \times 10^{-1}$ & 0.04 & 38.7 & $7-0.11$ & $9.8 \times 10^{-1}$ & 0.00 & 13.4 & 0.00 & $6.6 \times 10^{-1}$ & 0.04 & & -0.39 & $9.6 \times 10^{-1}$ & 0.00 & 13.9 & -0.07 \\
\hline Plot 4 & $3.2 \times 10^{-1}$ & 0.14 & $38.3-$ & -31.21 & $4.3 \times 10^{-1}$ & 0.09 & -60.7 & $7 \quad 0.32$ & $6.0 \times 10^{-1}$ & 0.04 & $16.6-$ & -0.01 & $1.5 \times 10^{-1}$ & 0.27 & $17.7-$ & -0.67 & $\mathbf{5 . 0} \times 10^{-2}$ & 0.44 & $20.8-$ & -1.50 \\
\hline Plot 5 & $1.1 \times 10^{-3}$ & 0.80 & -1.2 & 21.07 & $\mathbf{1 . 8} \times 10^{-3}$ & 0.77 & 80.3 & $3-0.28$ & $7.8 \times 10^{-1}$ & 0.01 & $15.4-$ & -0.01 & $9.3 \times 10^{-1}$ & 0.00 & 12.6 & 0.15 & $7.8 \times 10^{-1}$ & 0.01 & $15.5-$ & -0.59 \\
\hline
\end{tabular}

*WLS weights set to the inverse of $h_{\mathrm{wl}}$ pit variance. Significant $(p \leq 0.05)$ fits shown in bold. 
Table 4. WLS regression fits between $\tau_{\infty}$ and radiation estimates*

\begin{tabular}{|c|c|c|c|c|c|c|c|c|c|c|c|c|c|c|c|c|}
\hline \multirow{2}{*}{$\begin{array}{l}\text { Spatial } \\
\text { extent }\end{array}$} & \multicolumn{4}{|c|}{$\tau_{\infty} \sim L \downarrow$} & \multicolumn{4}{|c|}{$\tau_{\infty} \sim I_{\max }$} & \multicolumn{4}{|c|}{$\tau_{\infty} \sim \sum l$} & \multicolumn{4}{|c|}{$\tau_{\infty} \sim \sum t_{l}$} \\
\hline & $p$ & $r^{2}$ & $b$ & $m$ & $p$ & $r^{2}$ & $b$ & $m$ & $p$ & $r^{2}$ & $b$ & $m$ & $p$ & $r^{2}$ & $b$ & $m$ \\
\hline Plot 1 & $4.2 \times 10^{-1}$ & 0.10 & -2129.3 & 11.7 & $5.8 \times 10^{-1}$ & 0.05 & 919.7 & -1.2 & $4.6 \times 10^{-2}$ & 0.46 & 402.8 & 63.8 & $4.2 \times 10^{-2}$ & 0.47 & -7.5 & 165.8 \\
\hline Plot 2 & $3.6 \times 10^{-1}$ & 0.12 & -933.0 & 6.5 & $3.2 \times 10^{-1}$ & 0.14 & -306.9 & 3.6 & $2.6 \times 10^{-1}$ & 0.17 & 1000.0 & -97.0 & $8.5 \times 10^{-1}$ & 0.01 & 728.8 & -27.3 \\
\hline Plot 3 & $6.2 \times 10^{-1}$ & 0.04 & 2862.5 & -9.4 & $7.5 \times 10^{-1}$ & 0.02 & 926.9 & -1.2 & $2.3 \times 10^{-1}$ & 0.23 & 451.8 & 65.8 & $3.5 \times 10^{-1}$ & 0.15 & 271.9 & 104.6 \\
\hline Plot 5 & $4.6 \times 10^{-1}$ & 0.08 & -667.0 & 6.0 & $7.3 \times 10^{-1}$ & 0.02 & 915.0 & -0.7 & $2.6 \times 10^{-1}$ & 0.18 & 1294.3 & -118.0 & $3.3 \times 10^{-1}$ & 0.14 & 1280.0 & -134.2 \\
\hline
\end{tabular}

*WLS weights set to the inverse of $h_{\mathrm{wl}}$ pit variance. Significant $(p \leq 0.05)$ fits shown in bold.

vapor (Colbeck, 1988; Hachikubo and Akitaya, 1997; Cooperstein, 2008). The absence of moderate or strong winds also allows the necessary temperature gradient at the snow surface to develop (Nyberg, 1938; Colbeck, 1988; Hachikubo and Akitaya, 1997).

The subsequent plate-like crystals formed during a period dominated by diurnal patterns associated with solar-induced warming. Winds varied considerably during this time, but were generally strongest in the afternoon or early evening, subsiding to complete calm in the late evening or early morning. Irregularity in wind speed, indicated by the range in 10 min minimum and maximum recorded wind speeds (Fig. 4a), may have also fostered crystal growth by periodically resupplying vapor to the boundary layer without causing a temperature gradient to be diminished, as would occur under sustained winds (Colbeck, 1988).

During both surface hoar formation periods, $T_{\text {air }}$ at $1.5 \mathrm{~m}$ above the snow surface never dropped below $-5^{\circ} \mathrm{C}$ and often approached $0^{\circ} \mathrm{C}$ (Fig. 4c). Chalmers and Jamieson (2001) observed similar air temperatures during surface hoar formation. The development of pronounced temperature gradients at the snow surface (Nyberg, 1938; Kobayashi, 1961; Lang and others, 1984) could foster surface hoar development under these conditions.

Our work shows that on a northeast-facing slope at this latitude in the Northern Hemisphere, surface hoar can remain intact for many days despite high winds, relatively high air temperatures and direct shortwave radiation. While weather station data helped establish general meteorological conditions, the spatial patterns of wind and temperature were not observed or simulated. Such information would be valuable in future field studies examining the spatial distribution of surface hoar growth and persistence. Potential spatial patterns in winds may have resulted in trends of sensible heat flux and vapor transport across the study site, both of which would influence growth and persistence of surface hoar.

\section{Associations between incoming radiation and snowpack properties}

Within the $31 \mathrm{~m} \times 31 \mathrm{~m}$ study site, $h_{\mathrm{wl}}$ varied by a factor of 7 (3-22 mm) and was inversely correlated with spatial patterns of incoming radiation estimates. Shea and Jameson (2010) have also observed extreme variations in surface hoar thickness across sparsely forested terrain.

The shear strength, $\tau_{\infty}$, was positively correlated with exposure to shortwave radiation, $\sum l$ and $\sum t_{l}$, across plot 1 . Incoming longwave radiation inhibits surface cooling at night, a precondition for surface hoar formation, and shortwave radiation causes surface warming by day, which fosters crystal degradation. The inverse relationships between $L \downarrow$ and $h_{\mathrm{wl}}$ at plots 1,2 and 5 (Table 3) support previous associations identified by Gubler and Rychetnik (1991) and Höller (2001). Negative correlations between $h_{\mathrm{wl}}$ and $I_{\max }$ $\sum l$ and $\sum l_{t}$ were also identified (Table 3 ). Our estimates of $\sum l$ coincide with the minimum values in the surface hoar preservation regime observed by Feick and others (2007).

These findings support Gubler and Rychetnik's (1991) assertion that surface hoar formation will be most productive in places where both shading and sky visibility spatially coincide. In the Northern Hemisphere these microclimatic factors are easily coupled on forest openings on northerly aspects, where sky visibility and daytime shading coincide near the center of the openings and together encourage low surface temperatures throughout the night and day (Fig. 8). In addition, trees located at the base of such openings can receive intense solar radiation on their upslope boughs during the day, increasing re-radiation on the lower portion of the site and further enhancing the existing pattern of $L \downarrow$. Such factors could be well modeled using distributed radiation modeling (e.g. Adams and others, 2004).

In this dataset, spatial colinearity of longwave and shortwave radiation estimates made it difficult to discern whether one was more responsible for the spatial patterns of $h_{\mathrm{w}}$. Based on the following three characteristics, it is likely that both radiation types influenced the spatial patterns of $h_{\mathrm{wl}}$ : (1) correlations with both radiation types were significant, (2) all significant correlations were logical in the sign of the coefficients and (3) when the albedo of global shortwave radiation is accounted for (by multiplying $I_{\max }$ values by 0.1 , assuming an albedo of 0.9 ), the magnitude of the spatial variations of absorbed radiation is similar for long- and shortwave estimates.

Table 5. WLS regression fits between $\tau_{\infty}$ and $h_{\mathrm{wl}}{ }^{*}$

\begin{tabular}{llrrr}
\hline Spatial extent & $p$-value & $r^{2}$ & \multicolumn{1}{c}{$b$} & \multicolumn{1}{c}{$m$} \\
\hline Site & $9.7 \times 10^{-1}$ & 0.00 & 638.5 & 0.32 \\
Plot 1 & $4.1 \times 10^{-1}$ & 0.10 & 811.9 & -12.82 \\
Plot 2 & $3.0 \times 10^{-1}$ & 0.15 & 833.2 & -17.05 \\
Plot 3 & $\mathbf{2 . 8} \times 10^{-2}$ & 0.52 & 1364.2 & -52.12 \\
Plot 4 & $\mathbf{2 . 0} \times 10^{-2}$ & 0.56 & 2102.9 & -88.59 \\
Plot 5 & $9.4 \times 10^{-1}$ & 0.00 & 788.5 & -2.29 \\
& & & & \\
\hline
\end{tabular}

*WLS weights set to the inverse of $h_{\mathrm{wl}}$ pit variance; Significant $(p \leq 0.05)$ fits shown in bold. $p$-value is significance level, $r^{2}$ is explanatory strength, $b$ is $y$-intercept and $m$ is coefficient. 

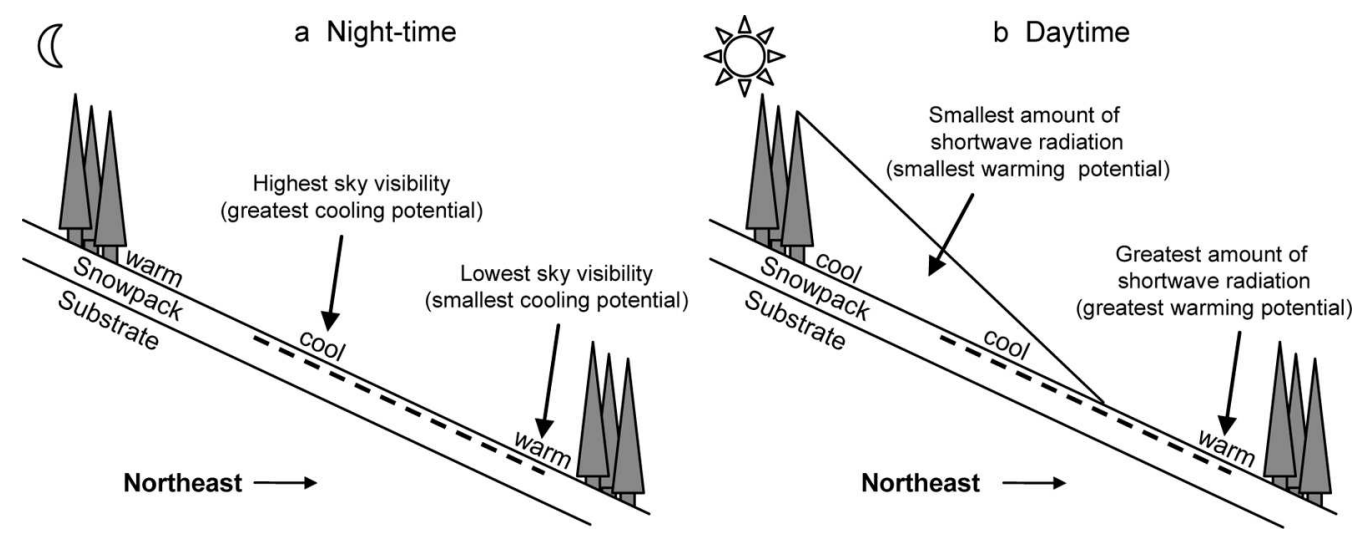

Fig.8. Conceptual model of (a) night-time and (b) daytime patterns in surface temperature on a northeast-facing (right) slope in the Northern Hemisphere. Bold dashed lines represent approximate upslope extent of study site.

\section{Associations between surface hoar thickness and shear strength}

Direct correlations between the spatial patterns of $h_{\mathrm{wl}}$ and $\tau_{\infty}$ were significant only at plots 3 and 4 . This was surprising given that both snow properties were spatially correlated with incoming radiation patterns. The lack of statistical significance may have been the result of the small sample sizes (six shear frames per pit, nine pits per plot).

Although here we examine the spatial patterns of the surface hoar properties, it is worth noting that no weak-layer thinning coincided with the observed shear strengthening over the 3 week-long sample period (Lutz, 2009). Chalmers and Jamieson (2001) also documented a young buried surface hoar layer that strengthened over 4 weeks despite no evidence of thinning during that period. Surface hoar strengthening is typically associated with thinning caused by inclination or penetration into the substratum (Davis and others, 1998; Jamieson and Johnston, 1999; Jamieson and Schweizer, 2000; Lutz and others, 2007). Our field observations indicate that the strengthening occurred at the transition with the superstratum. At initial conditions the surface hoar remained attached to the substratum after each shear test. As the sampling period progressed, the surface hoar ripped away from the substratum and remained attached to the superstratum (in the shear frame). Presumably the substratum interface would have strengthened more under a heavier slab load (Lutz, 2009).

\section{Implications for stability evaluation}

The observed spatial patterns of $h_{\mathrm{wl}}$ and $\tau_{\infty}$ highlight the conundrum that avalanche forecasters, ski patrollers and backcountry enthusiasts face when trying to choose and sample representative slopes or portions of slopes. Assessing stability at the edge of a forest opening, where the surface hoar is less developed than in the middle, can result in an overestimation of stability, or a false stable assessment. Yet sampling the middle of the slope, if steep enough, could be hazardous. On the other hand, if the observer finds any indication of unstable conditions at the edge of an opening, it is very likely that the buried surface hoar layer could be thicker and weaker in the middle to upper portion of the opening.

For researchers, these findings have ramifications for field-based snow studies. During the planning stage of field studies, scientists need to consider the potential for slopescale trends to be present, even on relatively uniform terrain. This is especially critical for temporal studies attempting to monitor changes in snowpack characteristics over time. Using our, or similar, sampling strategies, temporal studies can quantify and account for spatial patterns at initial conditions only if complex spatial patterns can be discerned and accounted for. This methodology could be applied to extensive high-resolution terrain, vegetation and snowpack surface models (e.g. Deems and Painter, 2006) to develop sampling strategies that eliminate potential colinearity of environmental determinants. This could be done a priori by modeling spatial patterns of radiation and other environmental factors before conducting snow observations. The spatial patterns of incoming radiation, although generated statistically, illustrate the complexity that vegetation and terrain introduce to the local conditions and the importance of incorporating spatial heterogeneity into process-driven snowpack and boundary layer modeling of surface hoar and near-surface faceted crystal formation (Lehning and others, 2002; Adams and others, 2004; Stössel and others, 2010).

\section{CONCLUSIONS}

Radiation estimates for the surface hoar formation period had pronounced spatial patterns that helped explain why the surface hoar layer was thin and strong at the base of the slope, and thick and weak at the middle to upper slope. At night, the lower slope received more incoming longwave radiation $(L \downarrow)$ than the upper slope because of re-radiation from downslope trees, which inhibits surface cooling and surface hoar formation. During the day, the lower slope received cumulatively more shortwave radiation $\left(\sum l\right)$ and also received more intense shortwave radiation $\left(I_{\max }\right)$ than the upper slope, thereby hindering the persistence of surface hoar in those areas. These spatial patterns and relationships can be identified across distances as short as $14 \mathrm{~m}$. Colinearity between shortwave and longwave variables made it difficult to determine which radiation variable was most critical. We also observed that surface hoar strengthening can occur over time without thinning.

In summation, this field study gives evidence that, in forest openings on northerly aspects, stability observations on the edges of the openings may overestimate slope-scale stability and should be treated as potentially the most stable condition. Further, researchers and forecasters conducting time-series observations in forest openings need to be mindful of the wide variation in surface hoar crystal sizes that can exist over short distances on these slopes. 


\section{ACKNOWLEDGEMENTS}

Many individuals provided us with valuable feedback, including K. Hansen Crawford, H.-P. Marshall, K. Kronholm, D. Myers and M. Schneebeli. We thank additional field crew members P. Bell, H. Buxton, K. Engelhardt, P. Jenkins, M. Klick, K. Kronholm, S. Leirfallom, S. Logan, R. LutzMountain, S. Moore and K. Scheler. We thank the Gallatin National Forest Avalanche Center for monitoring weak-layer development and for providing back-up snowmobiles. Two anonymous reviewers provided valuable feedback that helped clarify this paper. Partial funding for this work was provided by the US National Science Foundation's Geography and Regional Science (grant No. BCS-024310) and GK-12 programs.

\section{REFERENCES}

Adams, E.E., P. Gauer, L.R. McKittrick, A.R. Curran and D.S. Levenan. 2004. Modeling snow temperature in complex topography. In Ganju, A., ed., Proceedings of the International Symposium on Snow Monitoring and Avalanches, 12-16 April 2004, Manali, India. Manali, Snow and Avalanche Study Establishment, 87-96.

Bader, H., R. Haefeli, E. Bucher, J. Neher, O. Eckel and C. Thams. 1939. Der Schnee und seine Metamorphose. Beitr. Geol. Schweiz. 3. [SIPRE Transl. 14, 1954.]

Bader, H.P. and P. Weilenmann. 1992. Modeling temperature distribution, energy and mass flow in a (phase-changing) snowpack. I. Model and case studies. Cold Reg. Sci. Technol., 20(2), 157-181.

Bird, R.E. and R.L. Hulstrom. 1981. Simplified clear sky model for direct and diffuse insolation on horizontal surfaces. Golden, Colorado, Solar Energy Research Institute. (Technical Report SERI/TR-642-761.)

Birkeland, K.W. 2001. Spatial patterns of snow stability throughout a small mountain range. J. Glaciol., 47(157), 176-186.

Birkeland, K.W. and D. Chabot. 2006. Minimizing 'false-stable' stability test results: why digging more snowpits is a good idea. In Gleason, J.A., ed. Proceedings of the International Snow Science Workshop, 1-6 October 2006, Telluride, Colorado, USA. Telluride, CO, International Snow Science Workshop, 498-504.

Birkeland, K.W., K.J. Hansen and R.L. Brown. 1995. The spatial variability of snow resistance on potential avalanche slopes. J. Glaciol., 41(137), 183-190.

Birkeland, K., K. Kronholm and S. Logan. 2004. A comparison of the spatial structure of the penetration resistance of snow layers in two different snow climates. In Ganju, A., ed. Proceedings of the International Symposium on Snow Monitoring and Avalanches, 12-16 April 2004, Manali, India. Manali, Snow and Avalanche Study Establishment, 3-11.

Campbell, C. and B. Jamieson. 2007. Spatial variability of slab stability and fracture characteristics within avalanche start zones. Cold Reg. Sci. Technol., 47(1-2), 134-147.

Chalmers, T.S. and J.B. Jamieson. 2001. Extrapolating the skier stability of buried surface hoar layers from study plot measurements. Cold Reg. Sci. Technol., 33(2-3), 163-177.

Colbeck, S.C. 1988. On the micrometeorology of surface hoar growth on snow in mountainous area. Bound.-Layer Meteorol., 44(1-2), 1-12.

Conway, H. and J. Abrahamson. 1988. Snow-slope stability - a probabilistic approach. J. Glaciol., 34(117), 170-177.

Cooperstein, M. 2008. The effects of slope aspect on the formation of surface hoar and diurnally recrystalized near-surface faceted crystals. (MSc thesis, Montana State University.)

Cooperstein, M., K.W. Birkeland and K. Hansen. 2004. The effects of slope aspect on the formation of surface hoar and diurnally recrystalized near-surface faceted crystals: implications for avalanche forecasting. In Proceedings of the International Snow Science Workshop, 19-24 September 2004, Jackson Hole, WY, USA. International Snow Science Workshop, 83-93.

Cressie, N.A.C. 1993. Statistics for spatial data. New York, John Wiley.

Davis, R.E., B. Jamieson and C.D. Johnston. 1998. Observations on buried surface hoar in British Columbia, Canada: section plane analysis of layer evolution. In ISSW '98: International Snow Science Workshop, 27 September-1 October 1998, Sunriver, Oregon. Proceedings. Olympia, WA, Washington State Department of Transportation, 86-92.

Deems, J.S. and T.H. Painter. 2006. Lidar measurement of snow depth: accuracy and error sources. In Gleason, J.A., ed. Proceedings of the International Snow Science Workshop, 1-6 October 2006, Telluride, Colorado, USA. International Snow Science Workshop, 300-338.

Dozier, J. and J. Frew. 1990. Rapid calculation of terrain parameters for radiation modeling from digital elevation data. IEEE Trans. Geosci. Remote Sens., 28(5), 963-969.

Feick, S., K. Kronholm and J. Schweizer. 2007. Field observations on spatial variability of surface hoar at the basin scale. J. Geophys. Res., 112(F2), F02002. (10.1029/2006JF000587.)

Föhn, P.M.B. 1989. Snowcover stability tests and the areal variability of snow strength. In A merging of theory and practice: Proceedings of the International Snow Science Workshop, 12-15 October 1988, Whistler, British Columbia, Canada. Vancouver, B.C., Canadian Avalanche Association, 262-273.

Greene, E. and 10 others. 2009. Snow, weather, and avalanches: observational guidelines for avalanche programs in the United States. Second edition. Pagosa Springs, CO, American Avalanche Association.

Gubler, H. and J. Rychetnik. 1991. Effects of forests near the timberline on avalanche formation. IAHS Publ. 205 (Symposium at Vienna 1991 - Snow, Hydrology and Forests in High Alpine Areas), 19-38.

Hachikubo, A. and E. Akitaya. 1997. Effect of wind on surface hoar growth on snow. J. Geophys. Res., 102(D4), 4367-4373.

Höller, P. 2001. The influence of the forest on night-time snow surface temperature. Ann. Glaciol., 32, 217-222.

Iqbal, M. 1983. An introduction to solar radiation. New York, Academic Press.

Jamieson, J.B. 1995. Avalanche prediction for persistent snow slabs. (PhD thesis, University of Calgary.)

Jamieson, J.B. and C.D. Johnston. 1999. Snowpack factors associated with strength changes of buried surface hoar layers. Cold Reg. Sci. Technol., 30(1-3), 19-34.

Jamieson, B. and C.D. Johnston. 2001. Evaluation of the shear frame test for weak snowpack layers. Ann. Glaciol., 32, 59-69.

Jamieson, J.B. and J. Schweizer. 2000. Texture and strength changes of buried surface-hoar layers with implications for dry snow-slab avalanche release. J. Glaciol., 46(152), 151-160.

Johnson, J.B. and M. Schneebeli. 1999. Characterizing the microstructural and micromechanical properties of snow. Cold Reg. Sci. Technol., 30(1-3), 91-100.

Kobayashi, T. 1961. The growth of snow crystals at low supersaturations. Philos. Mag., 6(71), 1363-1370.

Kronholm, K. 2004. Spatial variability of snow mechanical properties with regard to avalanche formation. (PhD thesis, University of Zürich.)

Kronholm, K. and K.W. Birkeland. 2005. Integrating spatial patterns into a snow avalanche cellular automata model. Geophys. Res. Lett., 32(19), L19504. (10.1029/2005GL024373.)

Kronholm, K. and K.W. Birkeland. 2007. Reliability of sampling designs for spatial snow surveys. Comput. Geosci., 33(9), 1097-1110.

Kronholm, K. and J. Schweizer. 2003. Snow stability variation on small slopes. Cold Reg. Sci. Technol., 37(3), 453-465.

Kronholm, K., M. Schneebeli and J. Schweizer. 2004. Spatial variability of micropenetration resistance in snow layers on a small slope. Ann. Glaciol., 38, 202-208. 
Landry, C.C., K. Birkeland, K. Hansen, J. Borkowski, R.L. Brown and R. Aspinall. 2004. Variations in snow strength and stability on uniform slopes. Cold Reg. Sci. Technol., 39(2-3), 205-218.

Lang, R.M., B.R. Leo and R.L. Brown. 1984. Observations on the growth process and strength characteristics of surface hoar. In ISSW '84. A merging of theory and practice: International Snow Science Workshop, 24-27 October 1984, Aspen, Colorado. Proceedings. Aspen, CO, ISSW Workshop Committee, 188-195.

Lehning, M., P. Bartelt, B. Brown and C. Fierz. 2002. A physical SNOWPACK model for the Swiss avalanche warning. Part III: meteorological forcing, thin layer formation and evaluation. Cold Reg. Sci. Technol., 35(3), 169-184.

Logan, S., K. Birkeland, K. Kronholm and K. Hansen. 2007. Temporal changes in the slope-scale spatial variability of the shear strength of buried surface hoar layers. Cold Reg. Sci. Technol., 47(1-2), 148-158.

Lutz, E.R. 2009. Spatial and temporal analysis of snowpack strength and stability and environmental determinants on an inclined forest opening. (PhD thesis, Montana State University.)

Lutz, E., K.W. Birkeland, K. Kronholm, K. Hansen and R. Aspinall. 2007. Surface hoar characteristics derived from a snow micropenetrometer using moving window statistical operations. Cold Reg. Sci. Technol., 47(1-2), 118-133.

Lutz, E., K.W. Birkeland and H.P. Marshall. 2009. Quantifying changes in weak layer microstructure associated with artificial load changes. Cold Reg. Sci. Technol., 59(2-3), 202-209.

Marshall, H.P. and J.B. Johnson. 2009. Accurate inversion of highresolution snow penetrometer signals for microstructural and micromechanical properties. J. Geophys. Res., 114(F6), F04016. (10.1029/2009JF001269.)

McGill, R., J.W. Tukey and W.A. Larsen. 1978. Variations of box plots. Am. Statistician, 32(1), 12-16.

National Renewable Energy Laboratory (NREL). 2007. Solar Radiation Database 1991-2005 update: user's manual. Golden, CO, National Renewable Energy Laboratory. (Tech. Rep. NREL/TP581-41364.)
Nyberg, A. 1938. Temperature measurements in an air layer close to a snow surface. Geogr. Ann., 20(3-4), 234-275.

Perla, R. and T.M.H. Beck. 1983. Experience with shear frames. J. Glaciol., 29(103), 485-491.

Pielmeier, C. and H.P. Marshall. 2009. Rutschblock-scale snowpack stability derived from multiple quality-controlled SnowMicroPen measurements. Cold Reg. Sci. Technol., 59(2-3), 178-184.

Pielmeier, C. and M. Schneebeli. 2003. Snow stratigraphy measured by snow hardness and compared to surface section images. Cold Reg. Sci. Technol., 37(3), 393-405.

Schleiss, V.G. and W.E. Schleiss. 1970. Avalanche hazard evaluation and forecast, Rogers Pass, Glacier National Park. In Gold, L.W. and G.P. Williams, eds. Ice engineering and avalanche forecasting. Ottawa, Ont., National Research Council of Canada, 115-122.

Schneebeli, M. and J.B. Johnson. 1998. A constant-speed penetrometer for high-resolution snow stratigraphy. Ann. Glaciol., 26, 107-111.

Schneebeli, M., C. Pielmeier and J.B. Johnson. 1999. Measuring snow microstructure and hardness using a high resolution penetrometer. Cold Reg. Sci. Technol., 30(1-3), 101-114.

Shea, C. and B. Jamieson. 2010. Spatial distribution of surface hoar crystals in sparse forests. Natur Hazards Earth Syst, Sci., 10(6), $1317-1330$

Sommerfeld, R.A. 1984. Instructions for using the $250 \mathrm{~cm}^{2}$ shear frame to evaluate the strength of a buried snow surface. US DA Forest Serv. Res. Note, RM-446, 1-6.

Sommerfeld, R.A. and H. Gubler. 1983. Snow avalanches and acoustic emissions. Ann. Glaciol., 4, 271-276.

Stössel, F., M. Guala, C. Fierz, C. Manes and M. Lehning. 2010. Micrometeorological and morphological observations of surface hoar dynamics on a mountain snow cover. Water Resour. Res. 46(4), W04511. (1029/2009WR008198.)

Wilcoxon, F. 1945. Individual comparisons by ranking methods. Biometrics Bull., 1(6), 80-83.

Wilson, J.P. and J.C. Gallant, eds. 2000. Terrain analysis: principles and applications. New York, Wiley.

MS received 17 June 2010 and accepted in revised form 3 December 2010 